\title{
Impact of the H1N1 Influenza A virus epidemic on cancer treatment in Hyogo, Japan
}

\author{
Haruka Nakada' ${ }^{1}$ Masaharu Tsubokura' ${ }^{1}$ Tomoko Matsumura', Yuko Kodama ${ }^{1}$, \\ Masahiro Kami ${ }^{1}$, Hiroshi Nishimoto ${ }^{2}$ \\ 'Division of Social Communication System for Advanced Clinical Research, \\ Institute of Medical Science, University of Tokyo, Tokyo, Japan
}

${ }^{2}$ Cancer Information Services and Surveillance Division, Centre for Cancer Control and Information Services, National Cancer Centre, Tokyo, Japan

\begin{abstract}
The rapid spread of H1N1 influenza infection had impacts on healthcare systems. However, the impact on cancer treatment remains unknown. We sent questionnaires to 14 hospitals designated by the government as cancer treatment facilities in Hyogo and collected the following data: characteristics of hospitals, the number of cancer surgeries performed, establishment of specialized departments to treat $\mathrm{H} 1 \mathrm{~N} 1$ influenza patients, and the number of cancellations and postponements of surgeries. The study period was divided into three stages; the period from March 28 to May 15, 2009 as the pre-epidemic stage, that from May 16 to June 5 as the epidemic stage, and that from June 6 to July 3 as the post-epidemic stage. We compared the data collected during the three periods to investigate the influence of H1N1 influenza epidemic on cancer treatment. We received responses from $11(78.6 \%)$ hospitals. Of these, 10 were general hospitals with more than 300 beds and 1 was a cancer centre. Of the 11 hospitals, 7 (68.4\%) had established specialized departments to treat H1N1 influenza patients. Six hospitals had only outpatient departments and 1 had an outpatient department and an inpatient department. In 5 hospitals, surgeons were engaged in the treatment of H1N1 influenza patients. The number of cancellations or postponements in the pre-epidemic, epidemic and post-epidemic stage was 16, 10 and 7, respectively. No significant difference was found among the three periods in cancellation rate. H1N1 influenza epidemic did not directly influence the cancellation or postponement of performed for cancer patients. The impact of H1N1 influenza epidemic on the number of cancer surgeries performed was minimal.
\end{abstract}

\section{Key words}

Health Policy, Hospitalisation, Infectious Disease Reporting

\section{Corresponding author}

Haruka Nakada

Division of Social Communication System for Advanced Clinical Research, Institute of Medical Science, University of Tokyo, 4-6-1 Shirokanedai, Minato-ku, Tokyo, Japan

Email: nakurah-tky@umin.net 


\section{Introduction}

The World Health Organization (WHO) raised the pandemic alert level of $\mathrm{H} 1 \mathrm{~N} 1$ influenza $A$ to the highest level, i.e., phase 6 , on June $11,2009 .^{1}$ The H1N1 influenza virus infection rapidly spread throughout Japan after confirmation of the first case in the city of Kobe, Japan, on May 16. Various impacts of the rapid spread of this infection were observed in Japan-as per the orders of the local governments, more than 4,800 schools were closed; medical services were swamped; many companies declared bankruptcy; and the stock prices declined. ${ }^{2,3}$

There is little information on the influence of the pandemics of infectious diseases on healthcare utilization. Lu et al. estimated the changes in utilization of healthcare services between June 2002 and June 2003, during the severe acute respiratory syndrome (SARS) epidemic. ${ }^{4}$ They noted that the rate of elective procedures decreased by more than $50 \%$; however, the influence of the epidemic on procedures such as maintenance chemotherapy or radiotherapy and delivery was less. Another study reported that there was no change in the rate of urgent surgery; however, the rate of elective surgery decreased by $18 \%$ during the SARS epidemic. ${ }^{5}$

Recent studies have reported the impacts of H1N1 influenza infection on blood donation or emergency medical systems. ${ }^{6-7}$ However, its impact on cancer treatment remains unknown. Thus, we aimed to investigate whether the H1N1 influenza epidemic influenced the number of surgeries performed for cancer patients.

\section{Materials and methods}

We sent questionnaires to 14 hospitals designated by the government as cancer treatment facilities in Hyogo. The population of Hyogo prefecture, including that of its capital, Kobe City, is 5,600,000. Between April 25 and June 26, 2009, we collected information on the total number of surgeries performed for cancer patients, the number of specialized departments for treating patients with $\mathrm{H} 1 \mathrm{~N} 1$ influenza infection, and the number of cancelled or postponed surgeries and the causes of the same. The patients were not directly approached and no personal information was used either by the respondents or by us.
We defined the period from March 28 to May 15 as the pre-epidemic stage, that from May 16 to June 5 as the epidemic stage and that from June 6 to July 3 as the post-epidemic stage. We compared the data collected in the three stages with one another.

Chi-square test (performed using JMP software, version 8) and Tukey's method were used for the statistical analysis of the data, and a $p$ value of less than 0.05 was considered to be statistically significant.

\section{Results}

Table I summarizes the characteristics of the hospitals. We received responses to our questionnaire from 11 of the 14 (78.6\%) hospitals. Seven of the 11 hospitals had established specialized departments for treating patients with H1N1 influenza infection. All the 7 hospitals had specialized, outpatient departments but $1 \mathrm{had}$ an inpatient, specialized department for treating patients with $\mathrm{H} 1 \mathrm{~N} 1$ influenza infection.

During the study period, the total number of surgeries performed for cancer patients was 2,265. There was no significant difference among the three periods $(p=0.42)$ in terms of the cancellation data. We identified the following causes of cancellations and postponements of the surgeries: condition of the patient $(n=19)$, inconvenience of either the patient or his/her family $(n=11)$, change of therapy $(n=5)$, and other $(n=2)$. The H1N1 influenza epidemic did not influence the changes in patients' conditions or cancellation and postponement of the surgeries (Table II).

\section{Discussion}

The results of our study indicate that the impact of the H1N1 influenza epidemic on the number of the surgeries performed for cancer patients was minimal. The rate of surgeries that were cancelled or postponed in the pre-epidemic stage was $1.5 \%$; in other words, 1 surgery was cancelled or postponed every 1.9 days and that in epidemic stage was $1.9 \%$; in other words, 1 surgery was cancelled or postponed every 1.8 days. Furthermore, the rate of cancellation or postponement in the post-epidemic stage was $1.0 \%$. In other words, 1 surgery was cancelled or postponed every 2.9 days in the post-epidemic stage. 
Table I. The characteristics of the participating hospitals

\begin{tabular}{lrr} 
& Median & Range \\
\hline No. of beds $(\mathrm{n}=11)$ & 430 & $303-1006$ \\
\hline Category of hospital $(\mathrm{n}=11)$ & General hospital & $\mathbf{n}$ \\
\hline & Cancer centre & 10 \\
\hline $\begin{array}{l}\text { Specialized departments for treating patients } \\
\text { with H1N1 influenza infection }(\mathrm{n}=11)\end{array}$ & Outpatient department only & 6 \\
\hline & Outpatient and inpatient departments & 1 \\
\hline & None & 4 \\
\hline Hospitals with specialized departments $(\mathrm{n}=7)$ & Including surgeon & 5 \\
\hline
\end{tabular}

Table II. The effect of H1N1 influenza epidemic on patients' conditions, cancellation and postponement of the surgeries

\begin{tabular}{|c|c|c|c|}
\hline & Pre-epidemic & Epidemic & Post-epidemic \\
\hline Total no. of surgeries & 1081 & 507 & 677 \\
\hline No. of consultation days & 31 & 15 & 20 \\
\hline Cancelled or postponed surgeries & 16 & 10 & 7 \\
\hline \multirow{4}{*}{$\begin{array}{l}\text { Causes of cancellation or postponement } \\
\text { of the surgeries }(n=37)\end{array}$} & Patient's condition & $19(51.3 \%)$ & \\
\hline & $\begin{array}{l}\text { Inconvenience } \\
\text { of either the patient } \\
\text { or his/her family }\end{array}$ & $11(29.7 \%)$ & \\
\hline & Change of therapy & $5(11.5 \%)$ & \\
\hline & Other $^{+}$ & $2(5.4 \%)$ & \\
\hline
\end{tabular}

${ }^{+}$diagnostic workup and other surgery

The H1N1 influenza epidemic was not a direct cause of cancellation or postponement of cancer surgeries in any of the cases during the study periods. All the cancellations and postponements were attributable to patients' conditions and not to H1N1 influenza infection. No surgeries were cancelled or postponed due to infection of the medical staff with H1N1 influenza virus, although $\mathrm{H} 1 \mathrm{~N} 1$ influenza vaccination was not conducted in Japan during the study periods. ${ }^{8}$ The precaution to prevent nosocomial transmission of $\mathrm{H} 1 \mathrm{~N} 1$ influenza was recommended in parallel to that of SARS. ${ }^{9-10}$ The situations were quite in contrast to those observed during the SARS pandemic, when the rate of elective surgery decreased by $18 \% .^{5}$ Widespread restrictions on the non urgent use of hospital services were imposed during the SARS pandemic, because the 
mortality from SARS was approximately $15 \%$, which is apparently higher than that from H1N1 influenza infection. ${ }^{5,11}$ Although advanced age may be a risk factor of SARS, teenagers were the major targets of the H1N1 influenza epidemic, and approximately 20\% of the patients in whom this infection was confirmed were more than 20 years old. ${ }^{12-14}$ We think that most of the medical staff were above 20 years of age and were thus at a low risk of H1N1 influenza infection. Further, we think that even when a few of the medical staff contracted the infection, they were replaced by other healthy individuals.

The H1N1 influenza epidemic had a considerable impact on the surgeons' workload during the study period. Seven hospitals (64\%) had established specialized departments for treating patients with H1N1 influenza infection; in addition, surgeons were engaged in 5 of the 7 hospitals. In these hospitals, the surgeons provided care for patients with $\mathrm{H} 1 \mathrm{~N} 1$ influenza infection as well as for those who had undergone cancer surgeries. Despite the workload, all the surgeries were conducted at the scheduled time. It should be noted that 10 of the 11 hospitals were general hospitals with more than 300 beds, and that they probably had sufficient medical resources. The medical staff at these hospitals was capable of tackling the situation either by increasing the workload or by decreasing the quality of patient care. Cancer surgeries were conducted in large-scale general or specialized hospitals and might not have been affected by the H1N1 influenza epidemic.

This study provides some novel information on the care of cancer patients during the H1N1 influenza epidemic; however, this study has some limitations. This is a small-scale, retrospective study based on the findings obtained during the early stages of the epidemic in Hyogo. The possibility of unrecognized bias cannot be excluded. We focused on cancer surgeries, while further studies are required to determine whether $\mathrm{H} 1 \mathrm{~N} 1$ influenza has any effects on various types of surgical procedures other than cancer surgeries.

\section{Acknowledgments}

We appreciate Dr Ryosuke Tsuchiya's helpful suggestions.

\section{References}

1. WHO. World now at the start of 2009 influenza pandemic, vol. 2009.

2. Kyodo News. Flu scare could harm economy. The Japan Times online. http://search.japantimes.co.jp/cgi-bin/nb20090429a2. html [Accessed July 21, 2009]

3. Nakata H, Fukuda T. Flu virus starts to take toll on businesses Travel industry seen facing biggest risk. The Japan Times online. http://search.japantimes.co.jp/cgi-bin/nb20090523a3. html [Accessed July 21, 2009]

4. Lu TH, Chou YJ, Liou CS. Impact of SARS on healthcare utilization by disease categories: implications for delivery of healthcare services. Health Policy 2007; 83(2-3): 375-381. http://dx.doi.org/10.1016/j.healthpol.2007.03.001

5. Schull MJ, Stukel TA, Vermeulen MJ, et al. Effect of widespread restrictions on the use of hospital services during an outbreak of severe acute respiratory syndrome. CMAJ 2007; 176(13): 1827-1832. http://dx.doi.org/10.1503/cmaj.061174

6. Tsubokura M, Nakada H, Matsumura T, et al. The Impact of H1N1 Influenza A Virus Pandemic on the Blood Donations in Hyogo Prefecture, Japan. Transfusion 2010; 50(8): 1803-1805. http://dx.doi.org/10.1111/j.1537-2995.2010.02641.x

7. Tsubokura $M$, Nakada $H$, Matsumura $T$, Kodama $Y$, Kami M. The Impact of H1N1 Influenza A Virus Pandemic on the Emergency Medical Service in Kobe. Am J Emerg Med 2010; 28(2):248-251. http://dx.doi.org/10.1016/j.ajem.2009.10.013

8. Ministry of Health, Labour and Welfare, 2009. Vaccination Guideline for Pandemic Influenza.

9. Infectious Disease Surveillance Center, 2009. Infection Control for H1N1 influenza patients.

10. Infectious Disease Surveillance Center, 2009. Guidelines for SARS Infection Control (WHO) vol.3.

11. WHO, 2003. Consensus document on the epidemiology of severe acute respiratory syndrome (SARS).

12. Poutanen SM, Low DE, Henry B, et al. Identification of severe acute respiratory syndrome in Canada. $N$ Engl J Med 2003; 348(20): 1995-2005. http://dx.doi.org/10.1056/ NEJMoa030634

13. Shimada T, Gu Y, Kamiya $H$, et al. Epidemiology of influenza $\mathrm{A}(\mathrm{H} 1 \mathrm{~N} 1) \mathrm{V}$ virus infection in Japan, May-June 2009. Euro Surveill 2009; 14(24).

14. Nishiura H, Castillo-Chavez C, Safan M, Chowell G. Transmission potential of the new influenza $A(\mathrm{H} 1 \mathrm{~N} 1)$ virus and its age-specificity in Japan. Euro Surveill 2009; 14(22). 